\title{
NHE-1 Inhibitors and Erythropoietin for Maintaining Myocardial Function during Cardiopulmonary Resuscitation
}

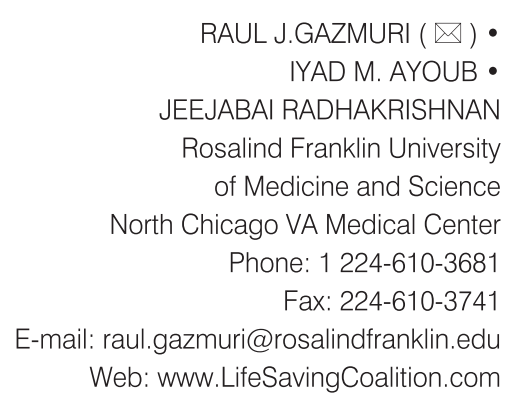

RAUL J.GAZMURI ( $₫) \bullet$ IYAD M. AYOUB • JEEJABAI RADHAKRISHNAN

Rosalind Franklin University of Medicine and Science North Chicago VA Medical Center Phone: 1 224-610-3681 Fax: 224-610-3741 E-mail: raul.gazmuri@rosalindfranklin.edu Web: www.LifeSavingCoalition.com

\section{RAÚL J. GAZMURI • IYAD M. AYOUB • JEEJABAI RADHAKRISHNAN}

\begin{abstract}
Efforts to successfully restore life in cardiac arrest victims are formidably challenging. They require not only that cardiac activity be initially reestablished but that injury to vital organs be prevented or minimized. In this article, we discuss the effects that cardiac arrest and resuscitation have on the myocardium, describing first the functional myocardial abnormalities that occur during cardiac resuscitation, which may limit the ability to reestablish cardiac activity. We then discuss strategies for minimizing myocardial injury and examine novel therapies aimed at minimizing ischemia and reperfusion injury. Finally, we discuss sodium-hydrogen exchanger isoform-1(NHE-1) inhibitors and erythropoietin for maintaining myocardial function during cardiopulmonary resuscitation.
\end{abstract}

Keywords: myocardial ischemic injury, reperfusion myocardial injury, cardiopulmonary resuscitation, NHE-1 inhibitors, erythropoietin

Myocardial Ischemic Injury during Cardiac Resuscitation

The working heart is a highly metabolic organ that under normal resting conditions extracts nearly $70 \%$ of the oxygen supplied by the coronary circulation $(1,2)$ representing close to $10 \%$ of the total body oxygen consumption. However, the heart has minimal capability for extracting additional oxygen, such that increases in metabolic demands can only be met by autoregulatory increases in coronary blood flow through vasodilatation of the coronary circuit. (3) Consequently, a severe energy imbalance develops when cardiac arrest occurs and coronary blood flow ceases. The severe energy imbalance continues during the ensuing resuscitation effort when current closed-chest resuscitation techniques are used because of the very limited capability for generating systemic and coronary blood flow. (4) The magnitude of the energy imbalance is contingent on the metabolic requirements and is particularly severe in the presence of ventricular fibrillation (VF) when the oxygen requirements are comparable to or exceed those of the normally beating heart. $(5,6)$ A lesser energy deficit is expected during cardiac arrest with a quiescent or minimally active heart (i.e., asystole or pulseless electrical activity precipitated by asphyxia or exsanguinations). Moreover, with reperfusion during resuscitation, multiple pathogenic mechanisms - collectively known as "reperfusi- on injury" - are activated and further contribute to myocardial injury. Main contributors to reperfusion injury are mitochondrial $\mathrm{Ca}^{2}+$ overload $(7,8)$ and generation of reactive oxygen species (ROS). (9)

The limited oxygen supply and concomitant reperfusion injury compromise the mitochondrial capability for regenerating ATP (adenosine triphosphate) through oxidative phosphorylation. Limited amounts of ATP; however, are generated at the substrate level from anaerobic glycolysis and breakdown of creatine phosphate. Taking these processes together, the myocardium develops a marked increase in lactic acid, rapid depletion of creatine phosphate, and relatively slow depletion of ATP during cardiac arrest and resuscitation. (10) Accordingly, the resuscitation effort typically proceeds - and occasionally succeeds - in the pre- 
sence of ischemia and in the midst of reperfusion injury.

Various functional myocardial abnormalities develop, consequent to ischemia and reperfusion, during cardiac arrest and resuscitation that exert effects detrimental to cardiac resuscitation. These abnormalities can be grouped into those that manifest during the resuscitation effort and those that manifest after the return of spontaneous circulation. The former include reductions in left ventricular myocardial distensibility and increased resistance to electrical defibrillation; the latter include reperfusion arrhythmias and post-resuscitation myocardial dysfunction. This discussion is focused on reductions in left ventricular myocardial distensibility and the extent to which its prevention can improve resuscitation and survival.

Reductions in Left VentricuIar Myocardial Distensibility during Cardiac Resuscitation

\section{Preclinical evidence}

Studies in various animal models of VF and resuscitation have shown progressive thickening of the left ventricular wall accompanied by parallel reductions in the left ventricular cavity without changes in intracavitary pressures during the resuscitation effort. $(11,12)$ A functionally similar phenomenon known as ischemic contracture - was reported in the early seventies during open heart surgery when operations were conducted under normothermic conditions and in fibrillating hearts $(13,14)$ and more recently after prolonged intervals of untreated VF. (15) However, ischemic contracture is associated with profound reductions in myocardial ATP and often leads to a "stony heart" heralding irreversible ischemic injury. (16)

Reductions in left ventricular myocardial distensibility, observed during cardiac resuscitation, is a different phenomenon: 1) it occurs much earlier than the "stony heart", 2) the onset and subsequent progression coincide with the interval of reperfusion during resus- citation, $(11,17) 3)$ it is associated with less ATP depletion, (10) 4) it has been attributed to myocardial energy deficit compounded by cytosolic and mitochondrial $\mathrm{Ca}^{2+}$ overload precluding complete relaxation of individual cardiomyocytes, 5) it evolves into diastolic dysfunction upon return of spontaneous circulation, (18) and 6) it is largely reversible. (19)

There are important hemodynamic consequences. As blood returns to the heart during the relaxation phase of chest compression, distensible ventricles are important to properly accommodate the returning blood and establish an adequate preload for the subsequent compression. The larger the distensibility, the larger the preload, and the larger the amount of blood that can be ejected by chest compression. This mechanism is akin to the Frank-Starling Law of the beating heart and presumes that blood is ejected from the left ventricle into the aorta during chest compression. Several experimental and clinical studies - using echocardiography - have documented that the heart is indeed compressed between the anterior chest wall and the spine and that during compression the mitral valve closes and the aortic valve opens. (20-22)

Progressive decreases in left ventricular myocardial distensibility during chest compression contribute to progressive decline in the hemodynamic efficacy of closed-chest resuscitation. Studies in a porcine model of VF have shown that the severity of this phenomenon is proportional to the duration of untreated VF. (11)

Work in our laboratory demonstrates that reductions in left ventricular myocardial distensibility can be prevented by pharmacologic interventions targeting reperfusion injury resulting in hemodynamically more stable closed-chest resuscitation. $(17,23)$ In our work we showed that progressive left ventricular wall thickening with reductions in cavity size were mitigated by administration of the sodium-hydrogen exchanger isoform-1 (NHE-1) inhibitor cariporide. (17) This effect prevented the hemodynamic deterioration that characteristically occurs during chest compression maintaining a stable coronary perfusion pressure above the resuscitability threshold of $10 \mathrm{mmHg}$ in pigs yielding higher resuscitation rates. (17)

\section{Clinical evidence}

Takino and Okada (24) reported in 1996 on 59 adult patients who suffered non-traumatic out-of-hospital cardiac arrest and underwent open-chest direct manual cardiac compression in the emergency department after failure of closed-chest resuscitation. A "firm" myocardium was noticed during manual cardiac compression in 36 cases affecting predominantly the left ventricle. In the remaining 23 cases the hearts were "soft." They also noted that some hearts became "firm" during compression.

The presence of a "firm" myocardium was associated with reduced hemodynamic efficacy of cardiac compression as evidenced by a lower endtidal $\mathrm{CO}_{2}$ tension (PETCO2) - which is a well documented surrogate measurement of systemic and regional blood flow during cardiac resuscitation. (4,2527) Hearts with "very firm" myocardium never regained spontaneous contractions. Hearts with "less firm" myocardium showed some, albeit insufficient, spontaneous contractions. Hearts with "soft" myocardium regained contractions and were able to generate a peripheral pulse in most instances.

\section{Other Myocardial Abnorma- lities during Resuscitation}

Notwithstanding the focus of the present discussion on left ventricular myocardial distensibility, the abnormalities succinctly described below share a common pathophysiological thread. Thus, interventions exerting an effect on left ventricular myocardial distensibility could also affect:

1) resistance to defibrillation (29)

2) reperfusion arrhythmia (30)

3) post-resuscitation myocardial dysfunction as previously reported to be the case associated with administration of NHE-1 inhibitors. (31-35)

Work in our research laboratory and 
subsequent clinical work in collaboration with Dr. Štefek Grmec, MD, PhD in Maribor, Slovenia demonstrates that these myocardial abnormalities in left ventricular dysfunction can be ameliorated by pharmacological intervention. We propose that this approach may represent a novel concept in resuscitation leading to new therapeutic interventions.

\section{Therapeutic Interventions}

Two lines of research, pointing to inhibitors of the NHE-1 and to erythropoietin as supporting the feasibility of the proposed approach, are discussed in this section. One line relates to work using NHE-1 inhibitors in various animal models of cardiac arrest over a period of approximately 10 years. $(10,17,23,28,36-55)$ Research over the last decade in our laboratory using various translational rat and pig models of cardiac arrest has shown consistent myocardial benefit associated with inhibition of NHE-1 activity during resuscitation from VF. $(10,17,23,28,37-41,56$ 60) Mechanistically, these benefits are associated with less cytosolic $\mathrm{Na}+$ overload, less mitochondrial Ca2+ overload, and preservation of oxidative phosphorylation. The other relates to more recent work using erythropoietin in a rat model of cardiac arrest (42) and in a small clinical study in patients suffering out-of-hospital cardiac arrest. (43) Both lines of research support the rationale and feasibility of using either an NHE-1 inhibitor or erythropoietin for preservation of left ventricular myocardial distensibility during cardiac resuscitation.

Effects of NHE-1 inhibition on resuscitation: Research over the last decade in our laboratory using various translational rat and pig models of cardiac arrest has shown consistent myocardial benefit associated with inhibition of NHE-1 activity during resuscitation from VF. (10,17,23,28,37-41,56-60) Mechanistically, these benefits are associated with less cytosolic $\mathrm{Na}+$ overload, less mitochondrial Ca2 + overload, and preservation of oxidative phosphorylation. Some of these studies, highlighting key aspects of NHE-1 inhibition during resuscitation, are succinctly discussed below.

The initial findings suggesting that NHE-1 inhibition could attenuate reductions in left ventricular myocardial distensibility during resuscitation and also prevent post-resuscitation diastolic dysfunction were made in an isolated (Langendorff) rat model of VF and simulated resuscitation. $(37,38)$

Subsequent studies were conducted in an intact rat model of VF and closedchest resuscitation and these studies also suggested that higher coronary perfusion pressures could be generated when administering a vasopressor agent given the larger blood flow generated in the presence of an NHE-1 inhibitor for a given compression depth. This was the case when cariporide was combined with epinephrine in our pig model (28) and when combined with epinephrine and with vasopressin in our rat model. (40)

Like in previous studies which used the NHE-1 inhibitor cariporide, (17) zoniporide also prevented reductions in left ventricular myocardial distensibility during the interval of VF and extracorporeal circulation, which in control pigs was characterized by progressive reductions in cavity size and progressive thickening of the left ventricular wall. These energy effects are consistent with NHE-1 inhibition protecting mitochondrial bioenergetic function - probably as a result of limiting mitochondrial $\mathrm{Ca} 2+$ overload - and supportive of the concept that left ventricular myocardial distensibility during resuscitation is likely to be preserved by activating mitochondrial mechanisms capable of maintaining bioenergetic function.

\section{Erythropoietin}

Cell mechanism: Erythropoietin is a 30.4-kDa glycoprotein best known for its action on erythroid progenitor cells and regulation of circulating red cell mass. However, several studies have recently shown that erythropoietin also activates potent cell survival mechanisms during ischemia and reperfusion through genomic and non-genomic signaling pathways in a broad array of organs and tissues including the heart, (61-66) brain, $(67,68)$ spinal cord, (69) retina, (70) kidney, (71) liver, (72) and skin. (73)

Activation of these protective mechanisms involves binding of erythropoietin to a specific cell membrane receptor, member of the type-I superfamily of single-transmembrane cytokine receptors, prompting cross-phosphorylation and activation of Janus tyrosine kinases (JAK) 1 and 2. Activation of JAK causes phosphorylation of tyrosine residues creating docking sites for the recruitment and activation of multiple signaling proteins that have Src-homology-2 (SH2) domains resulting in well-established anti-apoptotic, (62) anti-inflammatory, $(74,75)$ and proliferative effects (i.e., neovascularization) $(76,77)$ with time courses that vary contingent on the specific signaling mechanism and the duration of the erythropoietin binding to the EpoR (erythropetine receptors).

Although important in other settings, these effects are not likely to play a role for initial cardiac resuscitation. We hypothesize that erythropoietin is important for resuscitation by signaling through pathways that result in preservation of mitochondrial bioenergetic function leading to functional effects similar to those elicited by NHE-1 inhibition (albeit through quite distinct cell mechanisms). These mechanisms we hypothesize - involve activation of protein kinase $\mathrm{C}$ epsilon (PKCE) and protein kinase $B$ (Akt) as succinctly described below.

PKC $\varepsilon$ activation is a well established mechanism of myocardial protection believed to be responsible for preconditioning and acute protection. (78) PKCE is primarily located in the cytosol. Its phosphorylation by erythropoietin prompts translocation to the mitochondria where it could: 1) open putative mitochondrial ATP-sensitive K+ channels (KATP channels), $(79,80)$ 2) activate cytochrome c oxidase, (81) 3) activate aldehyde dehydrogenase, (82) and 4) inhibit the mitochondrial permeability transition pore. (83) Opening of KATP channels increases mito- 
chondrial $\mathrm{K}+$ conductivity. This is an energetically advantageous $(84,85)$ effect likely to limit mitochondrial Ca2+ overload (86) exerting effects similar to those of NHE-1 inhibition. Activation of cytochrome c oxidase (complex IV of the respiratory electron transport chain) could improve the efficiency of electron flow from cytochrome $\mathrm{c}$ to molecular oxygen enhancing the capability for ATP synthesis. Activation of aldehyde dehydrogenase (ADH2) could reduce the formation of toxic HNE-Michael adducts (4-hydroxy-trans-2-nonenal Michael adducts) and serve to preserve mitochondrial respiration.

Akt activation is a powerful survival signal that has been shown to mediate myocardial protection during late preconditioning and after reperfusion. (87) Erythropoietin mediates the phosphorylation of Akt through phosphorylation of phosphoinositide dependent kinase-1 (PDK1) upon activation of phosphatidylinositide kinase (PI3K). Activated Akt can translocate to mitochondria where it has been shown to exert beneficial effects including: 1) opening of mitochondrial KATP channels (87) with the anticipated effects as described above, 2) activation of respiratory chain complexes and FoF1 ATPase, (88) and 3) inhibition of the mitochondrial permeability transition pore. (89)

\section{Effects on resuscitation}

Studies in rats: The effects of erythropoietin were studied in our rat model of VF and closed-chest resuscitation using human recombinant erythropoietin (epoetin alpha, Amgen, Thousand Oaks, CA). (42) Rats were subjected to 10 minutes of untreated VF followed by 8 minutes of closed-chest resuscitation before attempting defibrillation. The depth of compression was adjusted to maintain an aortic diastolic pressure between 26 and $28 \mathrm{mmHg}$. This level of diastolic aortic pressure secured a coronary perfusion pressure above the resuscitability threshold of $20 \mathrm{mmHg}$ in rats. The relationship between the coronary perfusion pressure and compression depth (CPP/Depth) was used to assess changes in left ventricular myocardial distensibility. Successfully resuscitated rats were observed for 120 minutes before euthanasia.

Three groups of 10 rats each were randomized to receive a right atrial bolus of epoetin alpha $(5,000 \mathrm{lU} / \mathrm{kg})$ at baseline 15 minutes before induction of $V F$ (EPOBL -15-min), at 10 minutes of $V F$ before starting chest compression (EPOVF 10-min), or to receive $0.9 \%$ $\mathrm{NaCl}$ solution (control) instead with the investigators blind to the treatment assignment.

Erythropoietin given coincident with the beginning of chest compression after 10 minutes of untreated VF - but not before inducing VF - promoted hemodynamically more effective chest compression such that the CPP/Depth ratio averaged during the interval of chest compression was $2.0 \pm 0.3$ $\mathrm{mmHg} / \mathrm{mm}$ in EPOVF 10-min, $1.6 \pm 0.2$ $\mathrm{mmHg} / \mathrm{mm}$ in EPOBL -15-min, and 1.6 $\pm 0.3 \mathrm{mmHg} / \mathrm{mm}$ in the control group $(p<0.05$ EPOVF 10-min vs EPOBL -15-min and vs control). This difference represented a $25 \%$ improvement in the hemodynamic efficacy of chest compression with erythropoietin given at the beginning of chest compression.

The possibility that this effect resulted from a vasopressor action of erythropoietin seemed unlikely; baseline hemodynamic measurements in the group of rats that received erythropoietin 15 minutes before induction of VF (EPOBL -15-min) demonstrated a statistically borderline decrease (not increase) in systemic vascular resistance from $1.092 \pm 0.147$ to $1.010 \pm 0.133$ $\mathrm{mm} \mathrm{Hg} / \mathrm{mL} / \mathrm{min} / \mathrm{kg}$ ( $p=0.077$ by paired t-test).

Defibrillation restored spontaneous circulation in $8 \mathrm{EPOBL}$-15-min, $8 \mathrm{EPOVF}$ 10-min, and 9 controls. Post-resuscitation, EPOVF 10-min rats had significantly higher mean aortic pressure associated with numerically higher cardiac index and higher peripheral vascular resistance. The diminished effectiveneSs of erythropoietin when given before $V F$ is intriguing and worthy of additional investigation.

Studies in humans: A clinical study was performed in collaboration with Dr. Štefek Grmec, MD, PhD and colleagues at the Maribor Emergency Medical Services (EMS) system in the city of Maribor and adjacent rural areas encompassing a population of approximately 200,000 inhabitants. (43)

Resuscitation was attempted using regionally developed protocols that incorporate ILCOR 2005 recommendations by a two-tier system composed of basic life support (BLS) and advanced life support (ALS) teams with the latter led by a physician. Upon arrival of the ALS team the trachea was intubated - verifying proper placement by capnography - and positive pressure ventilation started with a tidal volume of approximately $6 \mathrm{ml} / \mathrm{kg}$ at 10 breaths per minute unsynchronized to compressions. The ALS team also established peripheral vascular access (within approximately 30 seconds). Patients assigned to erythropoietin received 90,000 IU of beta-epoetin (NeoRecormon, Hoffman La Roche) as a bolus within 1 or 2 minutes after starting chest compression followed by a 10-ml bolus of $0.9 \% \mathrm{NaCl}$. Beta-epoetin was kept refrigerated $\left(2-8^{\circ} \mathrm{C}\right)$ in the ambulance until immediately before use. In every instance erythropoietin was given before any other drug.

Patients who had return of spontaneous circulation were started on $0.9 \%$ $\mathrm{NaCl}$ solution cooled at $4^{\circ} \mathrm{C}(30 \mathrm{ml} /$ $\mathrm{kg}$ infused at $100 \mathrm{ml} / \mathrm{min}$ ) and given 0.08-0.10 mg/kg of vecuronium bromide (Norcuron ${ }^{\circledR}$, Organon) to initiate hypothermia while on route to the hospital. For hemodynamic stability, patients received dopamine $(5-10 \mathrm{mcg} /$ $\mathrm{kg} / \mathrm{min}$ ) for systolic blood pressure $<90$ $\mathrm{mmHg}$, dobutamine $(2.5-20.0 \mathrm{mcg} / \mathrm{kg} /$ min) for suspected cardiogenic shock, or if systolic blood pressure remained $<70 \mathrm{mmHg}$ despite the preceding measures norepinephrine $(8-12 \mathrm{mcg} /$ $\mathrm{kg} / \mathrm{min})$.

Upon hospital arrival patients were directly admitted to the Intensive Care Unit (ICU). Patients were cooled to a core temperature between 32 and $34^{\circ} \mathrm{C}$ by external means until they regained consciousness or had completed 24 
hours. Patients with ST-segment elevation myocardial infarction had percutaneous coronary interventions. Inotropic and vasopressor agents were infused guided by hemodynamic monitoring using a pulmonary artery catheter and transthoracic echocardiography.

Study groups: The study was originally designed as prospective and randomized. However, disruption in the supply of erythropoietin, prompted investigators to administer erythropoietin or $0.9 \%$ $\mathrm{NaCl}$ control based on availability, allocating 24 patients to erythropoietin and 30 to $0.9 \% \mathrm{NaCl}$ between April 2007 and May 2008. The control group for the analysis was designated as concurrent controls. Post-hoc, a second control group was included selecting 48 patients out of 126 patients who had out-of-hospital cardiac arrest treated with the same resuscitation protocol the year before. These 48 patients were selected using propensity scores assigning two controls for each erythropoietin-treated patient. Propensity scores were calculated using multiple logistic regressions; entering age, male sex, witnessed arrest, time from call to start CPR (cardiopulmonary resuscitation), pulseless electrical activity, asystole, and bystander CPR as pre-treatment predictors of outcome. The control group was designated as matched controls. The same variables used to calculate propensity scores were used to adjust odds ratios for the comparison between erythropoietin and the concurrent controls and between erythropoietin and the matched controls.

Results: By univariate analysis, administration of erythropoietin - when compared with concurrent controls was associated with higher rates of ICU admission, ROSC (resuscitation of spontaneous circulation), 24-hour survival, and survival to hospital discharge and - when compared with matched controls - it was associated with higher rates of ICU admission, ROSC, and 24-hour survival. After adjustment for pretreatment covariates (listed above), comparison with concurrent controls reduced the odds ratio but retained statistical significance for ICU admission and ROSC whereas comparison with matched controls increased the odds ratio demonstrating statistical significance for all four outcomes).

To assess whether the beneficial effects on resuscitation outcomes could have been linked to the beneficial effects on left ventricular myocardial distensibility - as suggested by our preceding study in rats (42) - we examine the effects on PETCO2. As discussed earlier, PETCO2 is a good surrogate measurement of forward blood flow during chest compression. (4,25-27) In the study, rescuers were trained and retrained to provide consistent depth and rate of compression and the values of PETCO2 in both control groups were already indicative of high quality chest compression. If - as hypothesized erythropoietin preserved myocardial distensibility, for a given compression depth, one would expect higher forward blood flow in the presence of erythropoietin and therefore higher $\mathrm{P}_{E T} \mathrm{CO}_{2}$. This was indeed the case. Victims who received erythropoietin had significantly higher $\mathrm{P}_{\mathrm{ET}} \mathrm{CO}_{2}$ during chest compression.

Because a single dose was administered, substantial effects on erythropoiesis were not anticipated. In fact, the hemoglobin and hematocrit in the present study were not statistically different than controls at 48 hours and at 72 hours.

Accordingly, these clinical observations - though based on a small sample size - are consistent with the hypothesis that erythropoietin - by preserving myocardial distensibility - leads to hemodynamically more effective chest compression resulting in higher resuscitation and survival rates.

\section{REFERENCES}

1. Binak K, Harmanci N, Sirmaci N, Ataman N, Ogan H. Oxygen extraction rate of the myocardium at rest and on exercise in various conditions. Br Heart J 1967;29:422-7.

2. Yusa T, Obara S. Myocardial oxygen extraction rate under general anesthesia. Tohoku J Exp Med 1981;133:321-4.

3. Hoffman JIE. Maximal coronary flow and the concept of coronary vascular reserve. Circulation 1984;70:153-9.

4. Duggal C, Weil MH, Gazmuri RJ,Tang W, Sun S, O'Conell F, et al. Regional blood flow during closed-chest cardiac resuscitation in rats. J Appl Physiol 1993;74:147-52.

5. Ditchey RV, Goto Y, Lindenfeld J. Myocardial oxygen requirements during experimental cardiopulmonary resuscitation. Cardiovasc Res 1992;26:791-7.

6. Gazmuri RJ, Berkowitz M, Cajigas H. Myocardial effects of ventricular fibrillation in the isolated rat heart. Crit Care Med 1999;27:1542-50.

7. Dong Z, Saikumar P, Weinberg JMI. Calcium in cell injury and death. Ann Rev Pathol 2006;1:405-34.

8. Halestrap AP. Calcium, mitochondria and reperfusion injury: a pore way to die. Biochem Soc Trans 2006;34(Pt 2):232-7.

9. Weisfeldt ML, Zweier J, Ambrosio G,Becker LC, Flaherty JT. Evidence that free radicals result in reperfusion injury in heart muscle. Basic Life Sci 1988;49:911-9

10. Ayoub IM, Kolarova J, Kantola R, Radhakrishnan J, Wang S, Gazmuri RJ. Zoniporide preserves left ventricular compliance during ventricular fibrillation and minimizes post-resuscitation myocardial dysfunction through benefits on energy metabolism. Crit Care Med 2007;35:2329-36. 
11. Klouche K, Weil MH, Sun S, Tang W, Povoas HP, Kamohara T, et al. Evolution of the stone heart after prolonged cardiac arrest. Chest 2002;122:1006-11.

12. Ayoub IM, Kolarova JD, Sehgal MA, Deshmukh H, Lubell DL, Franz MR, et al. Sodium-hydrogen exchange inhibition minimizes adverse effects of epinephrine during cardiac resuscitation. Circulation 2003;108:IV-420.

13. Cooley DA, Reul GJ, Wukasch DC. Ischemic contracture of the heart: "Stone Heart". Am J Cardiol 1972;29:575-7.

14. Katz AM, Tada M. The "Stone Heart": A challenge to the biochemist. Am J Cardiol 1972;29:578-80.

15. Sorrell VL, Altbach MI, Kern KB, Squire S, Hilwig RW, Hayes MM, et al. Images in cardiovascular medicine. Continuous cardiac magnetic resonance imaging during untreated ventricular fibrillation. Circulation 2005;111:e294.

16. Koretsune Y, Marban E. Mechanism of ischemic contracture in ferret hearts: relative roles of ŠCa2+Ći elevation and ATP depletion. Am J Physiol 1990;258:H9-H16.

17. Ayoub IM, Kolarova JD, Yi Z, Deshmukh H, Lubell DL, Franz MR, et al. Sodium-hydrogen exchange inhibition during ventricular fibrillation: Beneficial effects on ischemic contracture, action potential duration, reperfusion arrhythmias, myocardial function, and resuscitability. Circulation 2003;107:1804-9

18. Gazmuri RJ. Effects of repetitive electrical shocks on postresuscitation myocardial function. Crit Care Med 2000;28:N228-N232.

19. Gazmuri RJ, Deshmukh S, Shah PR. Myocardial effects of repeated electrical defibrillations in the isolated fibrillating rat heart. Crit Care Med 2000;28:2690-6.

20. Deshmukh HG, Weil MH, Gudipati CV, Trevino RP, Bisera J, Rackow EC. Mechanism of blood flow generated by precordial compression during CPR. I. Studies on closed chest precordial compression. Chest 1989;95:1092-9.

21. Kühn C, Juchems R, Frese W. Evidence for the 'cardiac pump theory' in cardiopulmonary resuscitation in man by transesophageal echocardiography. Resuscitation 1991;22:275-82.

22. Redberg RF, Tucker KJ, Cohen TJ, et al. Physiology of blood flow during cardiopulmonary resuscitation. A transesophageal echocardiographic study. Circulation 1993;88:534-42.

23. Kolarova JD, Ayoub IM, Gazmuri RJ. Cariporide enables hemodynamically more effective chest compression by leftward shift of its flowdepth relationship. Am J Physiol Heart Circ Physio. 2005;288:H2904-H2911.

24. Takino M, Okada Y. Firm myocardium in cardiopulmonary resuscitation. Resuscitation 1996;33:101-6.

25. Sanders AB, Atlas M, Ewy GA, Kern KB, Bragg S. Expired PCO2 as an index of coronary perfusion pressure. Am J Emerg Med 1985;3:147-9.

26. Gudipati CV, Weil MH, Bisera J, Deshmuckh HG, Rackow EC. Expired carbon dioxide: A noninvasive monitor of cardiopulmonary resuscitation. Circulation 1988;77:234-9.

27. Rubertsson S, Karlsten R. Increased cortical cerebral blood flow with LUCAS; a new device for mechanical chest compressions compared to standard external compressions during experimental cardiopulmonary resuscitation. Resuscitation 2005;65:357-63.

28. Ayoub IM, Kolarova J, Kantola RL,Sanders R, Gazmuri RJ. Cariporide minimizes adverse myocardial effects of epinephrine during resuscitation from ventricular fibrillation. Crit Care Med 2005;33:2599-605.

29. Valenzuela TD, Roe DJ, Nichol G, Clark LL, Spaite DW, Hardman RG. Outcomes of rapid defibrillation by security officers after cardiac arrest in casinos. N Engl J Med 2000;343:1206-9.

30. van Alem AP, Post J, Koster RW. VF recurrence: characteristics and patient outcome in out-of-hospital cardiac arrest. Resuscitation 2003;59:181-8

31. Gazmuri RJ, Weil MH, Bisera J, Tang w, Fukui M, McKee D. Myocardial dysfunction after successful resuscitation from cardiac arrest. Crit Care Med 1996;24:992-1000.

32. Kern KB, Hilwig RW, Rhee KH, Berg RA. Myocardial dysfunction after resuscitation from cardiac arrest: An example of global myocardial stunning. J Am Coll Cardiol 1996;28:232-40.

33. Laurent I, Monchi M, Chiche JD, Joly LM, Spaulding C, Bourgeois B, et al. Reversible myocardial dysfunction in survivors of out-of-hospital cardiac arrest. J Am Coll Cardiol 2002;40:2110-6.

34. Ruiz-Bailen M, Aguayo DH, Ruiz-Navarro S, Diaz-Castellanos MA, Rucabado-Aguilar L, Escudero GG, at al. Reversible myocardial dysfunction after cardiopulmonary resuscitation. Resuscitation 2005;66:175-81.

35. Xu T, Tang W, Ristagno G, Wang H, Sun S, weil MH. Postresuscitation myocardial diastolic dysfunction following prolonged ventricular fibrillation and cardiopulmonary resuscitation. Crit Care Med 2008;36:188-92.

36. Hilwig RW, Berg RA, Kern KB, Ewy GA. Endothelin-1 vasoconstriction during swine cardiopulmonary resuscitation improves coronary perfusion pressures but worsens postresuscitation outcome. Circulation 2000;101:2097-102.

37. Gazmuri RJ, Hoffner E, Kalcheim J, Ho H, Patel M, Ayoub IM, et al. Myocardial protection during ventricular fibrillation by reduction of proton-driven sarcolemmal sodium influx. J Lab Clin Med 2001;137:43-55.

38. Gazmuri RJ, Ayoub IM, Hoffner E, Kolarvo JD. Successful ventricular defibrillation by the selective sodium-hydrogen exchanger isoform-1 inhibitor cariporide. Circulation. 2001;104:234-9.

39. Gazmuri RJ, Ayoub IM, Kolarova JD, Karmazyn M. Myocardial protection during ventricular fibrillation by inhibition of the sodium-hydrogen exchanger isoform-1. Crit Care Med 2002;30:S166-S171. 
40. Kolarova J, Yi Z, Ayoub IM, Gazmuri RJ. Cariporide potentiates the effects of epinephrine and vasopressin by nonvascular mechanisms during closed-chest resuscitation. Chest 2005;127:1327-34.

41. Wang S, Radhakrishnan J, Ayoub IM, Kolarova JD, Taglieri DM, Gazmuri RJ. Limiting sarcolemmal Na+ entry during resuscitation from VF prevents excess mitochondrial Ca2+ accumulation and attenuates myocardial injury. J Appl Physiol 2007;103:55-65.

42. Singh D, Kolarova JD, Wang S, Ayoub IM, Gazmuri RJ. Myocardial protection by erythropoietin during resuscitation from ventricular fibriIlation. Am J Ther 2007;14:361-8.

43. Grmec S, Strnad M, Kupnik D, Sinkovic A, Gazmuri RJ. Erythropoietin facilitates the return of spontaneous circulation and survival in victims of out-of-hospital cardiac arrest. Resuscitation 2009;80:631-7.

44. von Planta M, Weil MH, Gazmuri RJ, Bisera J, Rackow EC. Myocardial acidosis associated with CO2 production during cardiac arrest and resuscitation. Circulation 1989;80:684-92.

45. Kette F, Weil MH, Gazmuri RJ, Bisera J, Rackow EC. Intramyocardial hypercarbic acidosis during cardiac arrest and resuscitation. Crit Care Med 1993;21:901-6.

46. Noc M, Weil MH, Gazmuri RJ, Sun S, Bisera J, Tang W Ventricular fibrillation voltage as a monitor of the effectiveness of cardiopulmonary resuscitation. J Lab Clin Med 1994;124:421-6.

47. Karmazyn M, Sawyer M, Fliegel L. The na $(+) / h(+)$ exchanger: a target for cardiac therapeutic intervention. Curr Drug Targets Cardiovasc Haematol Disord. 2005;5:323-35.

48. Imahashi K, Kusuoka H, Hashimoto K, Yoshioka J, Yamaguchi H, Nishimura T. Intracellular sodium accumulation during ischemia as the substrate for reperfusion injury. Circ Res 1999;84:1401-6.

49. Avkiran M, Ibuki C, Shimada Y, Haddock PS. Effects of acidic reperfusion on arrhythmias and $\mathrm{Na}(+)-\mathrm{K}(+)$-ATPase activity in regionally ischemic rat hearts. Am J Physiol 1996;270(3 Pt 2):H957-H964.

50. An J, Varadarajan SG, Camara A, Chen Q,Chen Q,Novalija E, Gross GJ, et al. Blocking $\mathrm{Na}(+) / \mathrm{H}(+)$ exchange reduces $[\mathrm{Na}(+)](\mathrm{i})$ and $[\mathrm{Ca}(2+)](\mathrm{i})$ load after ischemia and improves function in intact hearts. Am J Physiol 2001;281:H2398-H2409.

51. Gunter TE, Buntinas L, Sparagna G, Eliseev R, Gunter K. Mitochondrial calcium transport: mechanisms and functions. Cell Calcium 2000;28:285-96.

52. Yamamoto S, Matsui K, Ohashi N. Protective effect of $\mathrm{Na}+/ \mathrm{H}+$ exchange inhibitor, SM-20550, on impaired mitochondrial respiratory function and mitochondrial Ca2+ overload in ischemic/reperfused rat hearts. J Cardiovasc Pharmacol 2002;39:569-75.

53. Borutaite V, Brown GC. Mitochondria in apoptosis of ischemic heart. FEBS Lett 2003;541:1-5.

54. Nasser FN, Walls JT, Edwards WD, Harrison CE. Lidocaine-induced reduction in size of experimental myocardial infarction. Am J Cardiol. 1980;46:967-75.

55. Hinokiyama K, Hatori N, Ochi M, Maehara T, Tanaka S. Myocardial protective effect of lidocaine during experimental off-pump coronary artery bypass grafting. Ann Thorac Cardiovasc Surg 2003;9:36-42.

56. Gazmuri RJ, Ayoub IM. Myocardial Effects of Sodium-Hydrogen Exchange Inhibition during Resuscitation from Ventricular Fibrillation. In: Dhallas NS, Takeda N, Singh M, Lukas A, editors. Myocardial Ischemia and Preconditioning.Boston: Kluwer Academic Publishers; 2003. p. 375-88.

57. Gazmuri RJ, Ayoub IM, Kolarova J. Myocardial protection during resuscitation from cardiac arrest. Curr Opin Crit Care 2003;9:199-204.

58. Gazmuri RJ, Ayoub IM. The case for sodium-hydrogen exchanger isoform-1 inhibition during cardiac resuscitation remains strong. Crit Care Med 2006;34:1580-2.

59. Ayoub IM, Radhakrishnan J, Gazmuri RJ. Targeting mitochondria for resuscitation from cardiac arrest. Crit Care Med 2008;36:S440-46.

60. Radhakrishnan J, Ayoub IM, Gazmuri RJ. Activation of caspase-3 may not contribute to postresuscitation myocardial dysfunction. Am J Physiol Heart Circ Physiol 2009;296:H1164-74.

61. Cai Z, Manalo DJ, Wei G, Rodriguez ER, Fox-Talbot K, Lu H, et al. Hearts from rodents exposed to intermittent hypoxia or erythropoietin are protected against ischemia-reperfusion injury. Circulation 2003;108:79-85.

62. Parsa CJ, Matsumoto A, Kim J, Riel Ru, Pascal LS, Walton GB, et al. A novel protective effect of erythropoietin in the infarcted heart. J Clin Invest 2003;112:999-1007.

63. Tramontano AF, Muniyappa R, Black AD, Blendea MC, Cohen I, Denga L, et al. Erythropoietin protects cardiac myocytes from hypoxiainduced apoptosis through an Akt-dependent pathway. Biochem Biophys Res Commun 2003;308:990-4.

64. Parsa CJ, Kim J, Riel RU, Pascal LS, Thompson RB, Petrofski JA, et al. Cardioprotective effects of erythropoietin in the reperfused ischemic heart: a potential role for cardiac fibroblasts. J Biol Chem 2004;279:20655-62.

65. Wright GL, Hanlon P, Amin K, Steenbergen C, Murphy E, Arcasoy MO. Erythropoietin receptor expression in adult rat cardiomyocytes is associated with an acute cardioprotective effect for recombinant erythropoietin during ischemia-reperfusion injury. FASEB J 2004;18:1031-3.

66. Namiuchi S, Kagaya Y, Ohta J, Shiba N, Sugi M, Olkawa M, et al. High serum erythropoietin level is associated with smaller infarct size in patients with acute myocardial infarction who undergo successful primary percutaneous coronary intervention. J Am Coll Cardiol 2005; $45: 1406-12$.

67. Brines ML, Ghezzi P, Keenan S, Angello D, de Lanerolle NC, Cerami C, et al. Erythropoietin crosses the blood-brain barrier to protect against experimental brain injury. Proc Natl Acad Sci U S A 2000;97:10526-31. 
68. Ghezzi P, Brines M. Erythropoietin as an antiapoptotic, tissue-protective cytokine. Cell Death Differ 2004;11:S37-S44.

69. Celik M, Gokmen N, Erbayraktar S, Akhisarogolu M, Konakc S, Ulukus C, et al. Erythropoietin prevents motor neuron apoptosis and neurologic disability in experimental spinal cord ischemic injury. Proc Natl Acad Sci U S A 2002;99:2258-63.

70. Junk AK, Mammis A, Savitz SI, Singh M, Roth S, Malhotra S,et al. Erythropoietin administration protects retinal neurons from acute ischemia-reperfusion injury. Proc Natl Acad Sci U S A 2002;99:10659-64.

71. Vesey DA, Cheung C, Pat B, Endre Z, Gobe G, Johnson DW. Erythropoietin protects against ischaemic acute renal injury. Nephrol Dial Transplant 2004;19:348-55.

72. Abdelrahman M, Sharples EJ, McDonald MC, Coln M, Patel NS, Yaqoob MM, et al. Erythropoietin attenuates the tissue injury associated with hemorrhagic shock and myocardial ischemia. Shock 2004;22:63-9.

73. Buemi M, Vaccaro M, Sturiale A, Galeano MR, Sansotta C, Cavallari V,et al. Recombinant human erythropoietin influences revascularization and healing in a rat model of random ischaemic flaps. Acta Derm Venereol 2002;82:411-7.

74. Rui T, Feng Q, Lei M, Peng T, Zhang J, Xu M, et al. Erythropoietin prevents the acute myocardial inflammatory response induced by ischemia/reperfusion via induction of AP-1. Cardiovasc Res 2005;65:719-27.

75. Li Y, Takemura G, Okada H, Miyata S, Maruyama R, Li L, et al. Reduction of inflammatory cytokine expression and oxidative damage by erythropoietin in chronic heart failure. Cardiovasc Res 2006;71:684-94.

76. van der Meer P, Lipsic E, Henning RH, Boddeus K, van der Velden J, Voors AA, et al. Erythropoietin induces neovascularization and improves cardiac function in rats with heart failure after myocardial infarction. J Am Coll Cardiol 2005;46:125-33.

77. Hirata A, Minamino T, Asanuma H, Fujita M, Wakeno M, Myoishi M, et al. Erythropoietin enhances neovascularization of ischemic myocardium and improves left ventricular dysfunction after myocardial infarction in dogs. J Am Coll Cardiol 2006;48:176-84.

78. Holmuhamedov EL, Jovanovic S, Dzeja PP, Jovanović A, Terzic A. Mitochondrial ATP-sensitive K+ channels modulate cardiac mitochondrial function. Am J Physiol 1998;275(5 Pt 2):H1567-H1576.

79. Wald M, Gutnisky A, Borda E, Sterin-Borda L. Erythropoietin modified the cardiac action of ouabain in chronically anaemic-uraemic rats. Nephron 1995;71:190-6.

80. Liu H, Zhang HY, Zhu X, Shao Z, Yao Z. Preconditioning blocks cardiocyte apoptosis: role of K(ATP) channels and PKC-epsilon. Am J Physiol 2002;282:H1380-6.

81. Guo D, Nguyen T, Ogbi M, Tawfik H, Ma G, Yu Q, et al. Protein kinase C-epsilon coimmunoprecipitates with cytochrome oxidase subunit IV and is associated with improved cytochrome-c oxidase activity and cardioprotection. Am J Physiol Heart Circ Physiol 2007;293:H2219-30.

82. Chen CH, Budas GR, Churchill EN, Disatnik MH, Hurley TD,Mochly-Rosen D. Activation of aldehyde dehydrogenase-2 reduces ischemic damage to the heart. Science 2008;321(5895):1493-5.

83. Baines CP, Song CX, Zheng YT, Wang GW, Zhang J, Wang OL, et al. Protein kinase C-epsilon interacts with and inhibits the permeability transition pore in cardiac mitochondria. Circ Res 2003;92:873-80.

84. Ishida H, Hirota Y, Genka C, Nakzawa H, Nakaya H, Sato T. Opening of mitochondrial K(ATP) channels attenuates the ouabain-induced calcium overload in mitochondria. Circ Res 2001;89:856-8.

85. Light PE, Kanji HD, Fox JE,French RJ. Distinct myoprotective roles of cardiac sarcolemmal and mitochondrial KATP channels during metabolic inhibition and recovery. FASEB J 2001;15:2586-94.

86. Wang L, Cherednichenko G, Hernandez L, Halow J, Camacho SA, Figueredo V, et al. Preconditioning limits mitochondrial $\mathrm{Ca}(2+)$ during ischemia in rat hearts: role of K(ATP) channels. Am J Physiol Heart Circ Physiol 2001;280:H2321-8.

87. Ahmad N, Wang Y, Haider KH,Wang B, Pasha Z, Uzun O, et al. Cardiac protection by mitoKATP channels is dependent on Akt translocation from cytosol to mitochondria during late preconditioning. Am J Physiol Heart Circ Physiol 2006;290:H2402-8.

88. Shaik ZP, Fifer EK, Nowak G. Akt activation improves oxidative phosphorylation in renal proximal tubular cells following nephrotoxicant injury. Am J Physiol Renal Physiol 2008;294:F423-32.

89. Kobayashi H, Miura T, Ishida H, Miki T, Tanno M, Yano T, Sato T, et al. Limitation of infarct size by erythropoietin is associated with translocation of Akt to the mitochondria after reperfusion. Clin Exp Pharmacol Physiol 2008;35:812-9. 